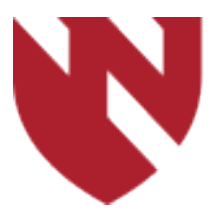

December 2019

\title{
An Unusual Presentation of Renal Cell Carcinoma with Tumor Thrombus
}

Joon S. Kim

University of Nebraska Medical Center

Paul Gribben

University of Nebraska Medical Center

Jennifer Fillaus

University of Nebraska Medical Center

Tell us how you used this information in this short survey.

Follow this and additional works at: https://digitalcommons.unmc.edu/gmerj

Part of the Higher Education Commons, and the Medicine and Health Sciences Commons

\section{Recommended Citation}

Kim, J. S., Gribben, P., , Fillaus, J. An Unusual Presentation of Renal Cell Carcinoma with Tumor Thrombus. Graduate Medical Education Research Journal. 2019 Dec 13; 1(1).

https://digitalcommons.unmc.edu/gmerj/vol1/iss1/71

This Conference Proceeding is brought to you for free and open access by DigitalCommons@UNMC. It has been accepted for inclusion in Graduate Medical Education Research Journal by an authorized editor of DigitalCommons@UNMC.For more information, please contact digitalcommons@unmc.edu. 


\section{An Unusual Presentation of Renal Cell Carcinoma with Tumor Thrombus}

Creative Commons License

(c) (i) ()

This work is licensed under a Creative Commons Attribution-Noncommercial-No Derivative Works 4.0 License. 


\section{An Unusual Presentation of Renal Cell Carcinoma with Tumor Thrombus}

Joon Soo Kim, Paul Gribben, Jennifer Fillaus

Mentor: Jennifer Fillaus

Program: Nephrology

Renal cell carcinoma (RCC) is the most common primary renal neoplasm. Here we present a patient with a 3 month onset of lower extremity swelling and worsening renal function found to be due to advanced $\mathrm{RCC}$ with extensive tumor burden and rapid subsequent decline.

A middle-aged patient was referred to nephrology clinic for proteinuria and an elevated creatinine from a baseline of 0.9 to $1.5 \mathrm{mg} / \mathrm{dL}$ over three months. The patient complained of bilateral leg swelling, shortness of breath, weakness, five-pound weight loss over the last 3 months. Vital signs were unremarkable. Physical examination was notable for $2+$ bilateral ankle edema. CMP was unremarkable except for a creatinine of $1.5 \mathrm{mg} / \mathrm{dL}$ and alkaline phosphatase of $581 \mathrm{U} / \mathrm{L}$ (100U/L three months ago). Urine protein/creatinine ratio was 4.29. Blood electrophoresis with immunofixation and free light chain ratio were all within normal range. The patient had normocytic anemia ( $\mathrm{Hgb} 9.8 \mathrm{mg} / \mathrm{dL}$ ), iron saturation of $10 \%$. Renal ultrasound revealed a thickened left renal cortex and poorly visualized left renal vein. Subsequent imaging revealed a $6 \mathrm{~cm}$ left renal mass with tumor thrombus in the left renal vein with extension into the IVC from the iliac vein bifurcation to the right atrium. A lytic lesion was noted in the L2 spine. A biopsy of the lytic lesion revealed metastatic clear cell RCC. The patient rapidly deteriorated from obstructive shock, acute renal failure, significant acidosis, congestive hepatopathy, and transudative ascites (with no tumor cells).

RCC should always be a part of the differential diagnosis when evaluating leg swelling, proteinuria, or elevated creatinine.

https://doi.org/10.32873/unmc.dc.gmerj.1.1.071

\section{Eculizumab for the Treatment of Recurrent C3 Glomerulonephritis Caused by C3 Gain of Function Mutation Joon S Kim, Ryan P Mullane, Scott Westphal, Eric Langewisch, Clifford Miles}

Mentor: Scott Westphal

Program: Nephrology

Introduction: C3 glomerulonephritis (C3GN) is a glomerular disease caused by excessive activation of the alternative complement pathway and often leads to end-stage renal disease. Following kidney transplantation, the recurrence risk is high and may cause premature allograft failure. Eculizumab prevents the membrane attack complex (MAC) formation and provides terminal complement inhibition. Here we present a case of early recurrent post-transplant $\mathrm{C} 3 \mathrm{GN}$ in a patient with a $\mathrm{C} 3$ gene mutation that was successfully treated with eculizumab.

Case Description: A middle-aged patient with a history of chronic kidney disease received a living unrelated kidney transplant. Prior to the transplant, the patient was diagnosed with $\mathrm{C} 3 \mathrm{GN}$ which was refractory to corticosteroids, mycophenolate, and rituximab. Evaluation revealed a $\mathrm{C} 3$ gain of function mutation. Complement inhibitory factors were normal and the patient did not have a C3 nephritic factor. An elevated level of soluble MAC (sMAC) was noted prior to transplantation. The patient had immediate graft function following transplant and was maintained on tacrolimus, mycophenolate, and prednisone following basiliximab induction. The patient's creatinine reached a nadir of $1.1 \mathrm{mg} / \mathrm{dl}$, but he/she developed early acute allograft dysfunction and proteinuria within the first few weeks of transplant and biopsy revealed early recurrence of $\mathrm{C} 3 \mathrm{GN}$. The patient was treated with high dose corticosteroids and plasmapheresis, but continued progression of renal dysfunction with rising sMAC levels, proteinuria, and activity of $\mathrm{C} 3 \mathrm{GN}$ on a repeat biopsy. After initiation of eculizumab, the sMAC levels normalized, proteinuria resolved, and the allograft function improved. The patient is now $>1$ year out from transplantation with stable allograft function and no evidence of complications related to the eculizumab.

Discussion: Eculizumab appears to have a role in select patients with recurrent $\mathrm{C} 3 \mathrm{GN}$. Since not all patients with $\mathrm{C} 3 \mathrm{GN}$ improve with eculizumab, more research is needed to define patients expected to benefit from this therapy. Patients with recurrent $\mathrm{C} 3 \mathrm{GN}$ due to a gain of function mutation in the $\mathrm{C} 3$ gene should be considered for early eculizumab therapy to preserve allograft function and decrease excessive complement activity. https://doi.org/10.32873/unmc.dc.gmerj.1.1.072

\section{Timing and Sequence of Chemoradiation for Low-Grade Gliomas Meeting RTOG 9802 Criteria} Jeffrey M. Ryckman, Adams Kusi Appiah, Elizabeth Lyden, Vivek Verma, Chi Zhang

Mentor: Chi Zhang

Program: Radiation Oncology

Purpose: Radiation Therapy Oncology Group (RTOG) 9802 has established postoperative radiotherapy (RT) and chemotherapy sequentially as the new standard of care for patients with high-risk low grade glioma (LGG) meeting trial criteria. Although all patients in the trial received sequential chemoradiation therapy (sCRT) with RT followed by chemotherapy, it is unknown whether concurrent chemoradiation therapy (cCRT) may offer advantages over sCRT.

Methods: The National Cancer Database (NCDB) was queried for newly-diagnosed World Health Organization (WHO) grade II glioma. Patients with unknown surgery, RT, or chemotherapy status were excluded, along with patients $<40$ years old who underwent gross total resection to coincide with RTOG 9802 exclusion criteria. Chi squared, Fisher's exact or Wilcoxon rank-sum tests evaluated differences in characteristics between groups. Kaplan-Meier analysis was used to evaluate overall survival (OS) between groups (sCRT vs. cCRT). Cox proportional hazards modeling determined variables associated with OS.

Results: In total, 496 patients were analyzed $(\mathrm{n}=416$ [83.9\%] cCRT, $\mathrm{n}=80$ [16.1\%] sCRT). Sequencing or concurrency of therapy did not independently influence survival on univariable/multivariable analysis. Factors associated with worse overall survival (OS) on multivariable analysis included advanced age $(p<0.001)$ while mixed glioma $(p=0.017)$ and oligodendroglioma $(\mathrm{p}=0.005)$ were associated with better OS than astrocytoma histologies.

Conclusions: This is the only known analysis of cCRT versus sCRT for LGG. There is no evidence that cCRT improves outcomes over sCRT.

https://doi.org/10.32873/unmc.dc.gmerj.1.1.073 